\title{
BUSINESS INTELLIGENCE INTEGRATED SOLUTIONS
}

\author{
Marian Pompiliu CRISTESCU \\ "Lucian Blaga" University of Sibiu, Romania \\ marian.cristescu@ulbsibiu.ro
}

\begin{abstract}
A Business Intelligence solution concerns the simple, real-time access to complete information about the business shown in a relevant format of the report, graphic or dashboard type in order help the taking of strategic decisions regarding the direction in which the company goes. Business Intelligence does not produce data, but uses the data produced by the company's applications. BI solutions extract their data from ERP (Enterprise Resource Planning), CRM (Customer Relationship Management), HCM (Human Capital Management), and Retail, eCommerce or other databases used in the company.
\end{abstract}

KEYWORDS: business intelligence, data minning, on-line analytical processing tools, data warehouse

\section{Introduction}

Business Intelligence (BI) is the process of collecting operational data and use these data to take the best decisions regarding the company. The BI software takes the information mass from the data sources of the company, integrates them, analyses them and presents timely verdicts in the form of reports, warnings and dashboards. These reports, warnings and dashboards provide a more accurate and evaluable view of the company's situation.

The success of a BI solution consists, in the end, in how much it helps the users, managers and technicians, in an organization to achieve the company's critical goals: achieving or exceeding revenue figures, seeking opportunities to reduce costs throughout the organization and maximize profitability by identifying the most profitable customers, most profitable products, services or programs.
Actually a Business Intelligence solution should be capable of providing evaluations that are simply impossible to get in other ways.

\section{Features of Business Intelligence} platforms

Gartner is a research and consulting organization IT at international level. Gartner's opinion as regards the most important software tender and how they are seen by organizations seeking platforms Business Intelligence (BI) for the development of BI applications.

Shoppers should evaluate the tenderers in all four quadrants, and not to consider that only the top companies of the quadrant can deliver successful BI implementations. Comparisons from one year to another of producer's positions particularly are not helpful because market dynamics (such as competitors, new products, new centers of acquisition) and 
the interests of the clients of the last magic quadrant have change (Schwarz, 2010).

That's why you want to evaluate, in the following figure (Sallam, Richardson, Hagerty \& Hostmann, 2011), the vendors who rely on this dynamic disposal and whose changes are reflected in the important magic quadrant criteria assessments. For the purposes of this analysis is defined by the function "Ability to Execute" (Schwarz, 2010) of a bidder score in five steps that Gartner has chosen them as the most important clients in the choice of supplier. This does not coincide with an increase in revenues, income or market share. "Completeness of vision" (Schwarz, 2010) is based on an assessment of the six key dimensions that is based including but not exclusively on product strategy.

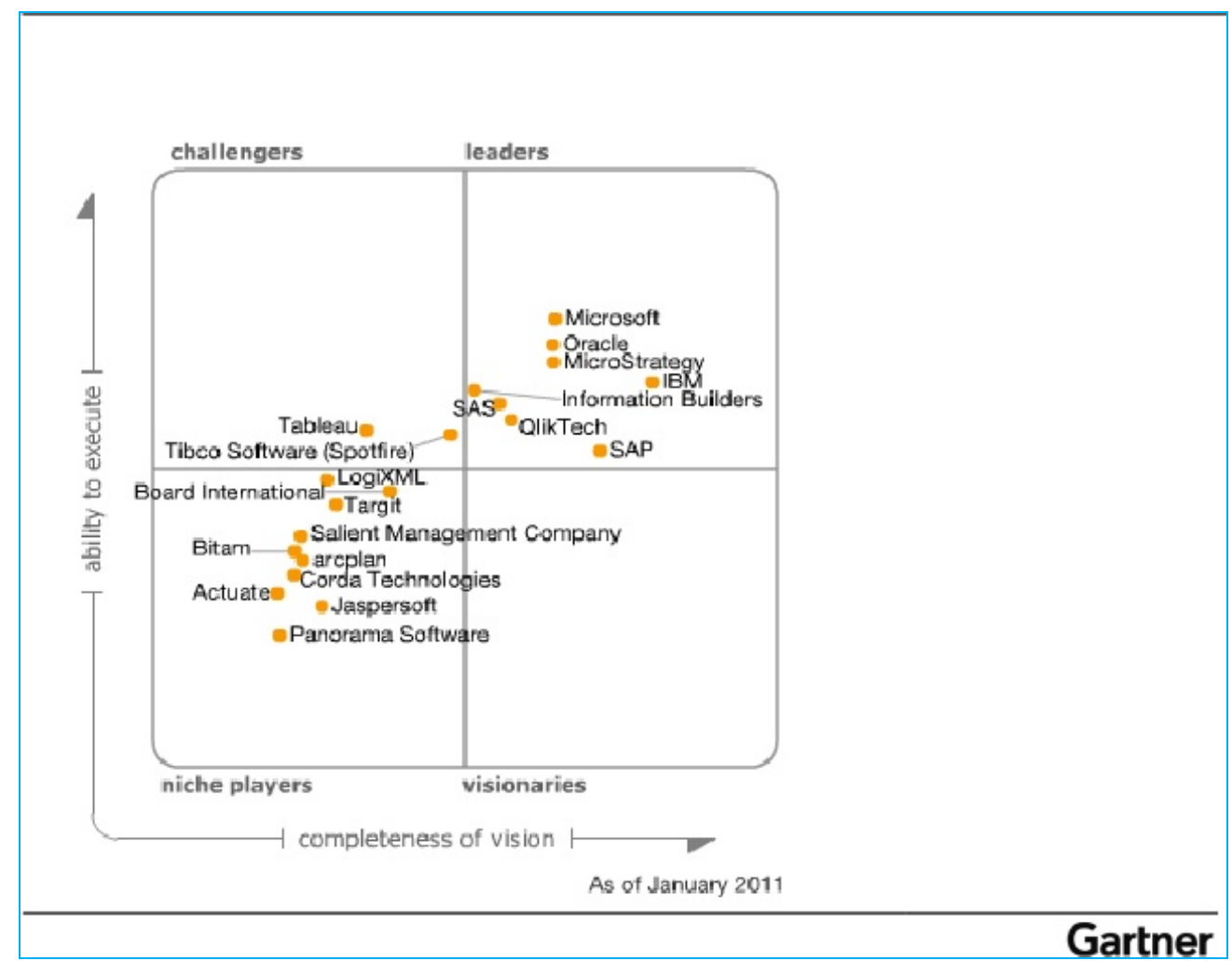

Figure no. 1: Magic quadrant from Gartner 2011

(source: Sallam, Richardson, Hagerty \& Hostmann, 2011)

\subsection{Strengths}

Microsoft has obtained the entire time BI market share from its difficult market entry in 2000. This was possible because the company has used BI functions, packaging and a tariff which are attractive for Microsoft developers and independent distribution partners. The company has invested, with consistency in the construction and improvement of the $\mathrm{BI}$ functions of the three essential offerings: Microsoft Office, Microsoft SQL Server and Microsoft SharePoint to increase their value.

By integrating the BI functions in the majority of Microsoft's ubiquitous products, it is practically guaranteed the continuously takeover of the BI functions, especially in organizations with an infrastructure of information centered on Microsoft. Based on questioning the customer magic quadrant Microsoft introduces this strategy with very much success, customers using an average of many keys related to the level of 
satisfaction between them sales experience and clients (including product quality and support), giving economic advantages for vendor success. Great satisfaction from customers with their approach is in its "Ability to Execute" position from Microsoft, (Microsoft Corporation, 2010a).

The strategy of concentrating license cost reduced to convince Microsoft BI platforms for enterprises who wish to provide a broader spectrum of BI users or who want to save BI portfolio costs in total with the help of the BI gear which are at an affordable price. Profile license is comparable with open source BI proposer and clearly lower than his competitors.

Whereas Microsoft introduces continuous functions in his BI products that most businesses already possess (Office, SQL Server and SharePoint), alternative functionality is becoming increasingly more complicated.

In the questionnaire for clients of the magic quadrant many customers Microsoft have shown the TCO (Total Cost of Ownership) (Microsoft Corporation, 2010a) as the most important reason for choosing Microsoft BI as the bidder, while the costs are indicated less frequently in the questionnaire as a barrier for a wider spread of Microsoft compared to most of the other tenderers. Market success of Microsoft comes partly from authoring tools (Microsoft Corporation, 2010a) geared towards IT from SQL Server, which has been established with the help of Visual Studio as a whole development environment.

This approach as well as concentrated marketing efforts and programmes for the construction of the community of developers and support have helped Microsoft to reduce costs and to extend the capabilities of Microsoft BI.

Customers of Microsoft BI platform infrastructure and appreciate the tools of Microsoft as the best compared to other bidders and a higher percentage of customers use them intensively.
In addition, the wide availability of powers is also a criterion for which customers are choosing Microsoft at the expense of competitors.

While Microsoft BI products have been labeled in the past as a solution for medium-sized enterprises in particular by Microsoft competitors, the Microsoft BI platform can be used for larger quantities of data and a much larger number of users.

Increasingly many customers see the BI platform from Microsoft as a standard in previous years. Using OLAP functionality (Microsoft Corporation, 2010b) by the customers of Microsoft is more than double compared to the rest of the questioned subjects.

This can be attributed to the success and functionality of retrieving Microsoft SQL Server Analysis Services with Microsoft SQL Server and Microsoft optimizations front-end Tools.

Organizations are addressing newer architectures In-Memory OLAP multidimensional relation to traditional OLAP architectures to support dynamic and interactive analysis of large amounts of data. Microsoft has used its first participation to the "In-Memory" (Microsoft Corporation, 2010b) by introducing Power Pivot and SQL Server with full memory Microsoft Analysis Services Cubes, which enable the analysis of level of subsecundă billion (in contrast to the hundreds of millions of lines today supported by PowerPivot), they will be available in the next version of SQL Server, code-named Denali (Microsoft Corporation, 2010b).

Microsoft is the only bidder BI platform that links its strategy BI platform closely collaborative Enterprise, SharePoint, which administer, seek and approve the mechanism by Microsoft BI content throughout the organization. Microsoft BI customers have a very positive image of the integrated approach to BI.

The new features of SharePoint 2010 search and social functions improved, open 
new opportunities for Microsoft and its partners in the further development of SharePoint for a decision to improve the quality and transparency of the common decisions.

\subsection{Weaknesses}

The complexity of multiple products is a challenge. In terms of Microsoft BI functions merge with Office and SharePoint, SQL Server requires that all three products to meet the requirements of BI platform complete, leading to adoption and the increased use of these three Microsoft products as well as for Windows systems. From the point of view of a user, for organizations that have these three technologies Microsoft, can build applications with tools that already possessed by the Organization, and whose employees are already familiar information. Whereas, however, the capabilities of the platform have three different BI tools that perform functions and non-necessary components, the integration of $\mathrm{BI}$ and construction applications are left to the discretion of the organization.

Microsoft's approach "do-it-yourself" (Schultz, 2006) gives freedom to the clients to develop BI solutions and to integrate the components of the platform more than BI platforms all-in-One of the many software vendors on the market. In comparison with its competitors, Microsoft has sea-facing BI users vision much more by developers. It begins with extensions to Microsoft Office and SQL Server PowerPivot capabilities that enable users of Excel for advanced ad-hoc analysis of larger quantities of data than ever before.

Whereas, however, the label of "do-ityourself” (Schultz, 2006) for BI, Microsoft doesn't provide analytical applications for Microsoft Dynamics or other enterprise applications, but the only toolkit for Microsoft Dynamics applications or rely on partners who build and sell these applications. In addition Microsoft has delayed the development of Microsoft Office PerformancePoint Server as "standalone" financial analysis applications (for example: planning, budgeting and consolidation) in favor of the integration of its functions with the CPM Dynamics AX 6.0 (Schultz, 2006). The result is that Microsoft is following other vendors (IBM, Oracle and SAP) with product strategyPerformance stand-alone. Instead Microsoft relies on partners to deliver CPM solutions based on Microsoft.

Product dependencies (for example between Microsoft SharePoint, Microsoft Office, and Microsoft SQL Server) coupled with long development cycles, hampering the ability of Microsoft to deliver innovations rapidly. These dependencies requires that the Microsoft BI platform client that has an external expertise with regard to the support and further development to buy the Microsoft technology Stack (Microsoft Corporation, 2010a). Marginal probability with Microsoft BI offerings depends on:

- how prepared is an organization to standardize technology end-to-end Microsoft infrastructure;

- purchase by the business users to Excel as a primary tool of BI;

- purchase by the IT Department of the Windows as the operating system;

- SQL Server as primary Data Warehouse;

- SQL Server Analysis Services as the primary multidimensional storage;

- Visual Studio and. NET as development environment;

- SharePoint Server as principal BI portal.

In reality, most organizations are living in a world of heterogeneous environments. The requirements of the Microsoft technology Stack (Microsoft Corporation, 2010a) to restrict its non-BI at Microsoft, while competing suppliers emphasizes openness and support for heterogeneous environments and optimize 
their data, applications and middleware platforms. In surveys of clients regarding the Microsoft BI platform of Gartner has year after year a below average score for his functions of metadata.

\section{Microsoft BI Platforms SWOT}

\section{Analysis}

Microsoft had, overall, a net turnover of 5.41 billion dollars in 2010, which corresponds to an increase of $51 \%$ over the previous year. In the evaluations of market share of Business Intelligence platforms (BI) from Gartner, (Schwarz, 2010), for 2010 Microsoft appears as the fourthlargest supplier after SAP Business Objects, SAS Institute and IBM Cognos.

Microsoft probably has a greater share in terms of users. In terms of global presence, Gartner BI platform that Microsoft has a market share of $9.6 \%$ in Europe, Middle East and Africa, $9.0 \%$ in America and is the market leader in Asia/Pacific with $20.9 \%$ of total turnover. Of course only about $10 \%$ of the products are sold as Microsoft BI stand-alone. Most of the revenue comes from the Microsoft BI platform functionality "boxed" in the database SQL-Server. Offer strategic BI platform has become to Microsoft because it runs on key products such as Windows, SQL Server, Office and SharePoint.

While the BI platform market settled down quickly, Microsoft has steadily gained a presence in the market through organic growth and growth through the acquisition small vendors such as Stratature and ProClarity whose workspace functionality can be easily contained in Microsoft's offer. Although Microsoft provides a low price and progress towards the integration of BI components, also provides spaces for the user friendly nature and scalability, based on Gartner research, Microsoft offers several ad hoc analysis, dashboarding and analytical applications, compared with other leading-edge vendors. In addition, since SQL-Server-divisions and Office-/SharePoint have not yet offered a product or strategy, BI platforms consisted of a fragmented and of the interfaces between the components of SQL Server BI, PPS and MOSS. The following table indicates the strengths, weaknesses, opportunities and risks that are characteristic of BI platforms Microsoft skills.

Table no. 1

\section{Microsoft BI platforms SWOT analysis}

\begin{tabular}{|c|c|}
\hline $\begin{array}{l}\text { Strengths } \\
\text { A compelling price model with functionality "good enough". } \\
\text { - BI platform offerings optimized for a Microsoft } \\
\text { technology stack } \\
\text { - A strong channel program } \\
\text { - Great quality product for new editions } \\
\text { - Strengths of BI platform components: Reporting, OLAP } \\
\text { (HOLAP/MOLAP), Scorecarding, Office Excel } \\
\text { integration, the integration of Predictive Analytics in the BI } \\
\text { platform components and common development } \\
\text { environment Visual Studio through SQL Server BI Tools }\end{array}$ & $\begin{array}{l}\text { Ssoft BI platform } \\
\text { PS and MOSS } \\
\text { llation, without } \\
\text { application and } \\
\text { nts } \\
\text { s the options for } \\
\text { roClarity users } \\
\text { ility only with } \\
\text { nvironment }\end{array}$ \\
\hline $\begin{array}{l}\text { current BI so } \\
\text { Microsoft fu } \\
\text { performance o } \\
\text { analysis tools }\end{array}$ & $\begin{array}{l}\text { Planning, } \\
\text { viewfinde }\end{array}$ \\
\hline
\end{tabular}




\section{Conclusions}

A Business Intelligence solution helps the user within an organization to achieve the following targets: achieving enterprisecritical or profit figures to be exceeded; maximizing profitability by identifying the most profitable programs; search for opportunities to reduce costs throughout the Organization; avoid overuse of IT resources, business-teams becoming more confident in their own forces; enabling faster and more effective use of IT for business and domestic customers, compiling a summary of 360 degrees geared towards customers.
A Business Intelligence solution makes it easy to the teams to understand the business data throughout the enterprise interaction and synthesize the results of the comprehensive review, trends and forecast results to understand the implications of these in-depth glances over the objectives of the enterprise. Business Intelligence users understand what happened, what is happening and what steps need to be taken in the future.

\section{REFERENCES}

Microsoft Corporation. (2010a). Online Documentation SQL Server 2008, Version: 10.5, available at: https://www.microsoft.com/en-us/download/details.aspx?id=9071.

Microsoft Corporation, TechNet Library, Deutschland (Deutsch) (2010b). Verwenden von Integration Services mit Analysis Services SQL Server 2008, reviewed in 2010, available at: https://technet.microsoft.com/de-de/library/ms403371(v=sql.100).aspx.

Sallam, R. L., Richardson, J., Hagerty, J., \& Hostmann, B. (2011). Magic quadrant for business intelligence platforms, Stamford, CT: Gartner Group.

Schultz, M. B., Knuth, J., \& Pruß, V. (2006). Microsoft SQL Server2005, Reporting Services - Das Praxisbuch, Microsoft Press Deutschland.

Schwarz, T. (2010). Business Intelligence als strategische Grundlage der Unternehmenssteuerung, available at: https://doi.org/10.1007/978-3-642-10276-9 28. 